\title{
Creativity and the Governance of Universities: Encounters of the Third Kind
}

\author{
GILI S. D R OR I \\ Department of Sociology and Anthropology, The Hebrew University of Jerusalem, \\ Mt. Scopus, Jerusalem, Israel 91905. Email: gili.drori@mail.huji.ac.il
}

Discussions of creativity and university governance often conflate multiple kinds of creativity-governance relations. Focusing on the 'third kind' of creativitygovernance relations in universities, I discuss the role of creativity in prospecting governance models. In other words, this paper focuses on the methods for creatively seeking (third kind) creative governance models (second kind) that foster academic creativity (first kind). I argue that the methods of prospecting governance models are subject to institutional dynamics that steer such search off the path of creativity. I note in particular two such institutional dynamics that track the prospecting process namely, professional expertise and referentiality - and I argue that these institutional dynamics generate inherent tension in the governance of creativity in universities. I illustrate these claims with findings from a large-scope research project on the branding of universities.

\section{Introduction}

Science springs from creative thinking, and academia blossoms when creativity is encouraged and subsidized. To allow for science and academia to thrive, policymakers and university leaders labour to design governance structures that, while regulating and administering science, do not tie a noose of red tape around its creative spirit. Therefore, policymakers and university leaders are concerned about the inherent tension between university governance structures (which increasingly take corporate governance as a model for effective administration and demand processes of measureable evaluation) and university missions (which declare the social role of universities as centres of creative scientific ventures, founded upon the ethos of academic freedom and the importance of basic science). However, such discussions of creativity and university governance often conflate multiple kinds of creativitygovernance relations. 
Specifically, creativity relates to university governance in three ways. In the first, creativity is conceived as the universities' output. From this perspective, universities are hubs for creative thinking, sources of novel models and products, and incubators for scientific and technological breakthroughs. Therefore, challenges come from the manner in which university governance directs and supports a university's role as a hub for creative thinking and doing. The second kind refers to creativity in university governance. Here, the burden of creativity is on governance itself, with a particular focus on the creativity of structures, practices, and behaviours in enabling universities' creativity. The third kind refers to the method of establishing the kind of creative governance that enables and supports universities' creativity. From this perspective, the challenge when fostering creativity is in seeking appropriate governance models in general - and, specifically, schemes of creative university governance that aims at enabling and supporting academic creativity. This paper orients the discussion of creativity and university governance towards this third kind; it is therefore guided by the question: what is creativity's place in the process of prospecting and establishing universities' governance models? The following analysis suggests several institutional processes that drive the search for universities' governance models. I draw on the specific governance mode of branding universities. Although branding is mostly concerned with universities looking creative and less about universities being creative, the penetration of branding practices into universities is a most illuminating example for the prospecting of 'best practice' models for university governance. Relying on examples from branding of universities, I identify two institutional factors that drive the prospecting for university governance models: the authority of expertise and referentiality. I argue that these institutional processes drive university leaders away from creative governance that fosters creative academia. In other words, I argue that institutional dynamics drive us to seek governance models in an uncreative manner, which, in turn, misdirects universities in their attempts to become well-governed hubs for social, scientific and technological creativity.

\section{The Three Kinds of Creativity-Governance Relations in Universities}

Unlike general workplaces, the innovation for which is often understood as springing from creative culture, ${ }^{1}$ universities are particularly endowed with innovation, novelty, and breakthroughs - and thus with creativity. Therefore, beyond the characteristics of the individual worker or scientist, and beyond the dynamics of the work or lab team, universities are understood to be organizations for, and of, creative activity. At either level of analysis, creativity is defined as idea generation that depends on the novelty and usefulness of those ideas, even if they are not necessarily linked to applications or implementations; creativity is thus distinct from innovation. ${ }^{2,3}$ Still, while there are several roadblocks in creativity research, ${ }^{4}$ much of the recent interest in creativity and organizations is driven by the definition of creativity as a precursor to innovation - and thus by creativity's contribution, however indirect, to economic and social progress. 5,6 
The insight that organizational success hinges on creativity and innovation is amplified with regard to universities, which, more than other knowledge-economy organizations, are oriented towards the production of creative ideas. This understanding draws upon the ethos of science and academia, which could be labelled organized scepticism, as excellence is defined by breakthroughs and by the novelty of ideas - even if most academic activity is closer to knowledge exploitation (incremental innovation) than to knowledge exploration (revolutionary science). ${ }^{7}$ As noted earlier, universities are considered hubs for creative thinking, sources of novel models and products, and incubators for scientific and technological breakthroughs. This is further fuelled by the recent redefinition of universities' social role; they are now considered active participants in the regional or global knowledge economy. ${ }^{8-10}$ In this way, the first kind of university creativity-governance tie is based on the idea that creativity is the universities' (and their administrations') output and that their goal is thus to foster creativity. While creativity is often thought of as being ungovernable in organizations, university administrations are nevertheless geared towards the governance of academic creativity, thus allowing researchers and scholars to excel as creative thinkers and to produce creative ideas.

University governance, especially during the past few decades of rapid global changes in academia, ${ }^{11,12}$ has faced challenges in navigating between the ethos of academic freedom and the rapidly expanding model of rationalized university management. On the one hand, academic autonomy has been sanctified as a core principal of academic identity for individual scientists and universities alike, thus ideologically securing depoliticized and unbiased research. ${ }^{13}$ On the other hand, university administration has been undergoing an intense managerialist transformation and has been penetrated by expansive rationalization and by related practices such as regulation, ${ }^{14,15}$ auditing and accountability, ${ }^{16}$ and quantification and ranking. ${ }^{17,18}$ This inherent tension between autonomy and managerialism has affected a variety of university administrative practices, ${ }^{19}$ not the least of which is the transformation of universities into modern, or hyper-rationalized, organizations, ${ }^{20-22}$ thus further empowering the hyper-rationalized form of university administration. ${ }^{23}$ One integral part of this mode of governance is the persistent drive towards change - the quest for creative ideas to improve administrative performance. While much of the literature on creative management focuses on leaders and top managers, ${ }^{24,25}$ pressure is mounting to adjust universities' governance modes - including technology, professionalization, and quality evaluation ${ }^{26,27}$ - so that universities can continue aiming for their longstanding goal of serving as hubs for creative science. In this way, the second kind of creativity-governance tie is focused on creative governance itself, and particularly on the use of creative university governance to allow universities to keep serving as creative hubs in spite of the inherent tension between academic autonomy and managerialism.

As university leaders and higher-education policymakers are concerned about how to identify appropriate governance models to fit with the global changes in universities, the third kind of creativity-governance tie is related to this quest for appropriate governance models. This third tie is concerned with methods for 
creatively seeking creative governance models that foster academic creativity emphasizing the threefold connection between creativity and the governance of universities. The focus in this third regard is not on creative output or on creative management but, rather, on the creative generation of appropriate university governance models. In this sense, this third kind of creativity-governance relations in universities has only an indirect impact on academic creativity: it is concerned with the process of forming and reforming governance practices, rather than necessarily with the output of such a governance regime. This indirect link with creativity is through the aspiration to secure creativity in university process and output (first kind) through establishing creativity-minded university governance (second kind) by infusing creativity into the search for models of university governance (third kind). As illustrated in the following analysis, this third kind of creativity-governance relations in universities is governed by institutional factors - specifically here, the authority of expertise and referentiality - which affect also other processes related to governance, in universities as in other organizations and with regard to creativity as with other initiatives. In the remainder of this paper, I draw on the example of university branding to illustrate the institutional dynamics that bound creativity in the process of prospecting and establishing university governance models.

\section{University Branding}

In line with the culture of 'the expressive organization', ${ }^{28}$ universities are increasingly consumed by strategizing their identities, managing their public reputations, and marketing their image in addition to their activities and services. As a result, branding has emerged as a common practice among higher education organizations, regardless of their national origin, academic scope, and size or capacity. ${ }^{29}$ Indeed, university branding campaigns that are similar in theme and procedure have been launched in the past two decades in countries as diverse as Finland, ${ }^{30}$ Germany, ${ }^{31}$ Hong Kong, ${ }^{32}$ Israel, ${ }^{33}$ Malaysia, ${ }^{34}$ Norway, ${ }^{35}$ Singapore,${ }^{36}$ Sweden $^{37}$ and the UK. ${ }^{38}$

Focusing specifically on the restyling of university iconography, Achim Oberg, Giuseppe Delmestri and I have identified several clear trends in university branding. ${ }^{39,40}$ First, we trace university branding initiatives that are widespread across the world, noting that such initiatives commonly feature a standard set of branding activities that, in addition to restyling the university's iconography, also include a brand book, trademarking, media campaigns and press releases. Second, we trace a change from emblems (iconographic styles that represent such abstract concepts as truth, enlightenment, or scholarship) to logos (branded iconographic styles that are concerned with recognition and visibility and with the translation of both these concepts into value). Third, while we identify four visualized identity narratives across 850 universities in 22 countries, the logo-stylized visualized identity narrative is currently overtaking the three emblematized narratives. Specifically, the logo-stylized organizational narrative, which removes the visualization in which the university is a distinct category of organization, is dominating university iconography worldwide. The emblematic guild-like classic narrative, the professional scientific narrative, and 
the localized narrative are all being increasingly marginalized. Lastly, while the three emblematic narratives are often intermingled, the recently dominant organizational narrative is often impermeable.

Such changes to university iconography are symbolic of a shift in university governance. The organizational narrative, which currently encompasses the largest category of visualized university identity, is governed by a managerialized ideology, according to which university administration and operations are disassociated from the particulars of the sector of higher education or of the local-national context. This narrative is highly rationalized, standardized, and professionalized; it is also marketized, commercialized, and medialized. ${ }^{41}$

In this manner, several sweeping social processes converge to bring 'brand society $^{, 42}$ into academia and to transform universities into branded (and branding) organizations. Overall, the dominant administrative insight among university leaders is that brand-based market differentiation has a direct impact on university recognition, but the recent branding frenzy among universities worldwide suggests that much of this drive comes from processes outside a given university or national academic field. Therefore, branding, instead of being instigated by university-specific capacities and conditions, is driven by universities' embeddedness within world society and by the global field of higher education:

The turning points of western, now global, civilization leave their mark on university iconography, by infusing their narrative with messages about religious erudition, Enlightenment, and the rise of the nation-state. The recent rise of 'brand society' is carried forward by globalization and its universalistic themes, by professionalization and rationalization that also penetrate university administration, by marketization and commercialization of knowledge that is also fuelled by assumptions about fierce global competition, and by mediatization which opens new venue for legitimacy strategies. ${ }^{41}$

Such embeddedness, which drives universities to adopt governance practices that are customary in their social contexts, is ripe for institutional dynamics that would mould university governance into a rational, yet rationalized form. These dynamics, as detailed in the following sections, could be used to track the process of prospecting and establishing university governance models that lack creativity.

Before moving on to the study of such institutional dynamics, I note that branding is not a critical practice for university governance in general or specifically for the governance of creativity in universities. Rather, as noted earlier, branding is more about making the university look creative, rather than about supporting or enabling creativity per se. Nevertheless, branding helps to mark, accentuate, symbolize, and visualize the institutional dynamics that steer the search for the creative governance of university creativity. Echoing Michael Power's commentary regarding the notion of impactfulness in universities, both branding and public relations practices illustrate a university's reorientation towards its external audiences, and this reorientation speaks either to the porousness of universities' boundaries or to science's socialization. ${ }^{43,44}$ Here, I use branding practices, which are just the tip of the iceberg for university managerialism, to illustrate the creativity traps in the processes of prospecting and establishing universities' governance models. 


\section{The Authority of Expertise}

The first institutional dynamic concerns the delegation of much university governance to professional experts. Branding, in universities as in other organizations, is a highly professional practice: its experts are part of a credentialed profession which relies on encoded professional knowledge and specified training and which is commonly divided into distinct administrative units. The intensifying authority of professional expertise is evident in the rapid expansion of organizational consultancy, ${ }^{45}$ and, more recently, in the rapid growth of branding consultancy, particularly related to education. ${ }^{46,47}$ Such professionalization of university branding is justified as prudent management in times of increased global competition among universities. I will illustrate how professional branding experts facilitate managerialism of the sort that causes the search for governance models to veer off track.

Professionalized branding acts in complex ways to affirm the institution of the university. Branding expertise decontextualizes the university: Professional branding experts reify the definition of the university as an organization like any other by applying schematic (or generic) branding strategies to universities. Therefore, through abstraction and modelling of best-practices routines - and, therefore, through theorization ${ }^{48}$ - professionalized branding practices reduce the uniqueness of the institution or of academia, while also affirming the university's position as a renewed and modern organization rather than an archaic 'ivory tower'.

The public embarrassment of two universities following their branding campaigns provides illustrations of the extent to which branding has been professionalized and of the authority that branding experts - rather than the academic faculty - have in making important decisions regarding universities' identities. The first such illustration is from Drake University's 2011 branding campaign in which the university replaced its long-standing emblem. That emblem was in the form of a seal and included traditional university insignia, such as the name of the university; a rising, beaming sun; an oil lamp (the latter two symbolizing the Enlightenment); an open book (symbolizing scholarship); and the year of the school's founding. For Drake University's 2011 marketing campaign, the seal was replaced with a 'D+' logo. The explanation for this choice was that the new logo symbolizes 'the Drake advantage' that alumni and students experience, but the logo's association with a subpar grade triggered public shaming of the institution's leaders; within days, the campaign was foiled, and the seal was reinstituted as the sole icon of Drake University. ${ }^{39}$

Similar embarrassment was brought upon Université Laval of Quebec, Canada, during its 2016 fundraising and alumni campaign to celebrate the university's 350th anniversary. Université Laval's emblem recalls the coat of arms of the House of Laval, in honour of the university's namesake, Saint François de Laval, who was the first Bishop of Quebec: the emblem is in the form of a shield, with eagle and shell images organized around a cross, and it is coloured with the traditional Laval red and gold. The 2016 posters, which were simultaneously posted as full-page ads in several Quebec newspapers, reduced this complex emblem to a single image of an eagle, which was soaring high to symbolize excellence and was trailed by three gold and red lines. 
Within hours of the ads' appearance, bloggers started noting the resemblance of this image to the image of the Nazi Pavilion at the 1937 International Exposition in Paris. The Nazi Pavilion - which was designed by the prominent German architect Albert Speer, who later served as Minister of Armaments and War Production during the Second World War - is a 150-metre tall stone tower, topped by an eagle and a Nazi swastika; it is also marked by three vertical linear crevices. Within days, the bloggers' intense outrage fuelled widespread newspaper reporting, which, in turn, drove Université Laval's officials to immediately stop the advertising campaign, returning to it only after the posters were redesigned with the traditional coat of arms placed above the three red and gold vertical lines.

Both of these cases involve old, traditional universities that, like many others worldwide, were swept up in the spread of branding over the past decade. While these universities' turns towards branding were fuelled by managerialism and by their professionalization in general, their campaigns reveal the extent to which this professionalization drives universities to leave important identity-related discussions in the hands of professional branding experts. Rather than involve academic faculty, for whom the university is their professional home - and who would therefore be sensitive to the cultural cues related to failing grades or to detested political ideologies branding decisions were placed in the hands of branding experts, who were immersed in branding know-how regarding aesthetics, marketing, and media appeal. This caused one blogger to ask, 'Is there no faculty of history at Laval University?"49 Academic faculty contribute to such managerialist tendencies: they gladly abstain from involvement with governance decisions because the academic ethos valorizes research and teaching rather than administrative duties. In this way, the academic ethos enables the grip that professional managers and management experts, with their management knowledge, have on university governance.

\section{Referentiality}

How do universities reach the decision to rebrand, and how do they decide the form that a new logo should take? Part of the strategic exercise that commonly precedes a branding campaign is benchmarking, which involves surveys to determine the steps that the industry's best take. The determination of comparable universities is guided by institutions' reputations for excellence and for leadership in a given field; this process is increasingly based on rankings. Therefore, benchmarking is tied to the search for the elusive defining standards of a world-class university. ${ }^{50}$ In addition, benchmarking is considered to accelerate productivity because it allows for universities to learn from the mistakes and successes of model universities. More abstractly, benchmarking is also a reflection of rationalization's use in university governance, as it carries the discourses of cause-and-effect and organizational learning (which are essential to organizational reform), as well as the practices of quality assurance, efficiency, and accountability that embody such managerialist logics.

This codified set of practices, which is known as strategic benchmarking, is a process of establishing referentiality; through this process, universities identify their 
corresponding organizations, acknowledge their social categories, and define their success or failure. While the explicit aims of benchmarking strategies is focused on rational management, ${ }^{51}$ benchmarking also codifies a university's identity claims. During benchmarking exercises, university leaders answer the questions 'who we are', 'who we are not', and most importantly 'who we want to be'. ${ }^{52}$ Specifically, such questions pertain to whether the institution is comparable to research universities or to colleges; to globally recognized universities or to regional and local universities; and to multiversities or to single-faculty universities. Interestingly, as public and private science increasingly intermingle, universities and business increasingly cooperate - and best practices are transferred through the porous boundaries of these categories $^{53,54}$ - the universities' identity claims, as expressed (for example) in their mission statements, remain firmly bound to academia and to their core missions of teaching, research, and social import. University iconography, on the other hand, increasingly references a generalized organizational model; as noted earlier, many universities are rebranding and using logo-style icons that are stripped of any symbolic references to an academic ethos or to locality. ${ }^{41}$

Colloquially, referentiality could be termed 'the Harvard-of syndrome' because many universities set Harvard as their idealized model and glibly take upon themselves the tag 'Harvard of _': 'Harvard of the South' (Vanderbilt University), 'Harvard of the Middle East' (The Hebrew University of Jerusalem), 'Harvard of China' (Peking University), or 'Harvard of Taiwan' (National Taiwan University). Singularity University, which was founded in 2008 to fashion a novel model of corporate university, is dubbed the 'Harvard of Silicon Valley'. 'Harvard-of' referencing also serves as an arena for performing the competition between comparable universities; for example, Stanford University, which is often referred to as the 'Harvard of the West', is jesting with the recent labelling of Harvard University as 'Stanford of the East.' This type of nickname, or tag, referencing is sometimes reinforced with other branding practices, some of which are deliberately planned by university leaders. For example, in 2014, during Facebook's Doppelgänger Week, when Facebook members changed their profile pictures to those of the celebrities that they most resembled, The Hebrew University of Jerusalem playfully participated by replacing the profile image of its official emblem with the official emblem of Harvard University. In this good-humoured way, while still cautious not to violate Harvard University's proprietary rights to its logo, The Hebrew University performed its referencing: it proclaimed its identity as a Harvard-like - and therefore world-class and renowned, as well as the first in its land - research university. Such identity assertions are consequential far beyond branding: a Harvard-like self-image may also express itself in other strategy proposals, some of which more closely touch upon curricular and research matters. For example, the simple matter of redesigning The Hebrew University's logo - which required stylistic representations of various faculties and the stylistic differentiation of the nested units of faculty, department, and institute - drove discussions of disciplinary demarcation and hierarchies of knowledge. In these ways, presumably minor administrative decisions impact core features of the institution of the university. 
Regarding the third kind of creativity-governance relations, the playfulness of tag-line referentiality and the sombreness of the benchmarking strategy only thinly conceal the impact that such practices have on the methods for seeking governance models - here, those of universities. Referentiality signals that, even when universities initiate reform to create organizational change, they rely on templates borrowed from (idealized) comparable universities. Two matters are key to this compromise of creativity. The first is the reliance on templates, which are abstractions from the particular causes of success and prestige. Because it does not consider the particulars, a generalized scheme rarely delivers the hoped-for results and often erases the university's unique features or its competitive edge. The second is the process of idealizing comparable universities, which is essentially a process in the construction of university excellence. While academic excellence is conceived as meritocratic and is increasingly metricized, 'constructions of excellence are connected to the reproduction of inequalities in the academic system'; ${ }^{35,56}$ rather than being value-neutral, definitions of academic excellence trace hierarchies of centrality and marginality (which, for universities, follow Western meanings). Through abstraction into schematic models and the construction of a universal standard of excellence, referentiality narrows the scope of the creative search for creative university governance that can enable academic creativity.

\section{Concluding Comments}

The challenge facing leaders of academia lies in creatively prospecting governance models for creatively navigating towards academic creativity. The contemporary preoccupations that policymakers and university leaders have with creativity and governance parallel their concern with 'innovating' innovation. Both creativity and innovation - which touch upon the governance of organizational change in general are increasingly managed by professionals and made up of professional knowledge, and they are thus subject to institutional dynamics. Such institutional dynamics specifically, professional expertise and referentiality - generate inherent tension in the governance of creativity. On the one hand, professional management prioritizes creativity and advances related practices, but on the other hand, managerialism locks creativity in the iron cage of organizational practices. As Wilf explains, highlighting the impact that such professionalization has on the reproduction and reinforcement of existing patterns:

As the explosion of the field of business innovation suggests, routinized innovation represents a new cultural-organizational ethos that emphasizes constant generation of newness, new cultural knowledge that consists of systematic strategies of such generation, and new cultural artifacts that result from the application of such strategies. It is an engine of cultural evolution that might be responsible for a faster pace of such evolution. ${ }^{57}$

With illustrations from universities' recent enthusiasm for branding, I expose the institutional dynamics that have led to the lack of creativity in university governance. The global branding trend among universities is driven by, and carries the cultural 
tones of, managerialism (logics and practices of administration and authority that determine organizational structure and behaviour), mediatization (logics and practices of communications that shape publicness and visibility), and marketization (exchange logics and practices that pertain to such notions as competition, profitability, and value). These trends are predicated upon professionalization - the formulation of task-relevant knowledge and of related skills - which is often complemented by certification and demarcation from other professional groups. With regard to university branding, professionalization has infused both university administrations and the branding sector. Contemporary social pressures encourage universities to become more socially relevant and socially productive, thus perforating the boundaries of academia and making universities particularly susceptible to managerialism, mediatization, and marketization and transforming universities into promotional entities. ${ }^{58}$ More generally, the universities' perforated organizational boundaries enable governance models to flow toward those institutions from other sectors and other organizations.

The institutional dynamics that govern universities' publicity, marketing and branding are also highly relevant for other practices within university management and governance. Such administrative tasks as human resources practices (e.g. hiring and promotion), financial practices (e.g. budgeting and solvency), and academic tasks (e.g. grading and admissions) are also based on such institutional principles. In this respect, these institutional dynamics dominate, not the specific activity, but the process of governance and strategy; here, the dynamics pertain to the authority of professional experts. In highlighting institutional dynamics, I steer the explanation away from human error and blame; I also do not claim that the experts to whom the governance tasks are delegated are acting mindlessly. Rather, my aim is to highlight how schematic thinking, which is at the core of professional strategy-making, is a trap when the goal is creativity. In this regard, it is the process of seeking a governance model that befits the creative governance of a creativity-inducing university that is itself uncreative.

\section{Acknowledgements}

This study was generously supported by the Israel Science Foundation (Grant No. 812/12) and by the European Commission's Marie Curie Career Integration Grant (PF7-People-2012 322041). I thank my research partners, Professor Giuseppe Delmestri and Dr Achim Oberg, and Professor Lars Engwall for their thoughtful comments on earlier drafts of this manuscript.

\section{References and Notes}

1. N. Anderson, K. Potočnik and J. Zhou (2014) Innovation and creativity in organizations: A state-of-the-science review, prospective commentary, and guiding framework. Journal of Management, 40(5), pp. 1297-1333.

2. N. Anderson, C.K.W. De Dreu and B.A. Nijstad (2004) The routinization of innovation research: A constructively critical review of the state-of-the-science. Journal of Organizational Behavior, 25(2), pp. 148-149. 
3. S. Yusuf (2009) From creativity to innovation. Technology in Society, 31(1), pp. $1-8$.

4. R.J. Sternberg and T.I. Lubart (1999) The concept of creativity: Prospects and paradigms. In: R.J. Sternberg (Ed.), Handbook of Creativity (Cambridge: Cambridge University Press), p. 4.

5. M.A. Peters, S. Marginson and P. Murphy (2009) Creativity and the Global Knowledge Economy (New York: Peter Lang).

6. J.M. George (2007) Creativity in organizations. The Academy of Management Annals, 1(1), pp. 439-477.

7. J.G. March (1991) Exploration and exploitation in organizational learning. Organization Science, 2(1), pp. 71-87.

8. H. Etzkowitz and L. Leydesdorff (2000) The dynamics of innovation: From national systems and 'mode 2' to a triple helix of university-industrygovernment relations. Research Policy, 29(2), pp. 109-123.

9. J. Youtie and P. Shapira (2008) Building an innovation hub: A case study of the transformation of university roles in regional technological and economic development. Research Policy, 37(8), pp. 1188-1204.

10. E. Deiaco, A. Hughes and M. McKelvey (2010) Universities as strategic actors in the knowledge economy. Cambridge Journal of Economics, 36(3), pp. 525-541.

11. C. Mazza, P. Quattrone and A. Riccaboni (Eds) (2008) European Universities in Transition: Issues, Models and Cases (Cheltenham: Edward Elgar Publishing).

12. J.G. Wissema (2009) Towards the Third Generation University: Managing the University in Transition (Cheltenham, UK: Edward Elgar Publishing).

13. M. Henkel (2005) Academic identity and autonomy in a changing policy environment. Higher Education, 49(1), pp. 155-176.

14. F.O. Ramirez and T. Christensen (2013) The formalization of the university: Rules, roots, and routes. Higher Education, 65(4), pp. 695-708.

15. J.G. March, M. Schulz and X. Zhou (2000) The Dynamics of Rules: Change in Written Organizational Codes (Stanford, CA: Stanford University Press).

16. C. Shore (2008) Audit culture and illiberal governance: Universities and the politics of accountability. Anthropological Theory, 8(3), pp. 278-298.

17. S. Marginson and M. Van der Wende (2007) To rank or to be ranked: The impact of global rankings in higher education. Journal of Studies in International Education, 11(3-4), pp. 306-329.

18. E. Hazelkorn (2015) Rankings and the Reshaping of Higher Education: The Battle for World-Class Excellence (Basingstoke: Springer).

19. For example, strategic thinking. S. Oertel and M. Söll (2016) Universities between traditional forces and modern demands: The role of imprinting on the missions of German universities. Higher Education, 73(1), pp. 1-18.

20. G. Krücken and F. Meier (2006) Turning the university into an organizational actor. Globalization and Organization: World Society and Organizational Change. G.S. Drori, J.W. Meyer and H. Hwang (Eds), (Oxford: Oxford University Press), pp. 241-257.

21. E. Ferlie, C. Musselin and G. Andresani (2009) The governance of higher education systems: A public management perspective. In: C. Paradeise, E. Reale, I. Bleiklie and E. Ferlie (Eds), University Governance (Basingstoke: Springer), pp. 1-20.

22. F.O. Ramirez (2010) Accounting for excellence: Transforming universities into organizational actors. In: V. Rust, L. Portnoi and S. Bagley (Eds), Higher Education, Policy, and the Global Competition Phenomenon (Basingstoke: Springer), pp. 43-58. 
23. C. Musselin (2013) How peer review empowers the academic profession and university managers: Changes in relationships between the state, universities and the professoriate. Research Policy, 42(5), pp. 1165-1173.

24. J.-P. Deschamps and B. Nelson (2014) Innovation governance: How top management organizes and mobilizes for innovation. Management, 42, p. 3.

25. M.D. Mumford, G.M. Scott, B. Gaddis and J.M. Strange (2002) Leading creative people: Orchestrating expertise and relationships. The Leadership Quarterly, 13(6), pp. 705-750.

26. C.M. Christensen and H.J. Eyring (2011) The Innovative University: Changing the DNA of Higher Education from the Inside Out (New York: Wiley).

27. D. Schejbal (2012) In search of a new paradigm for higher education. Innovative Higher Education, 37(5), pp. 373-386.

28. M. Schulz, M.J. Hatch and M. Holten Larsen (Eds) (2000) The Expressive Organization: Linking Identity, Reputation, and the Corporate Brand (Oxford: Oxford University Press).

29. G. Delmestri, A. Oberg and G.S. Drori (2015) The unbearable lightness of university branding: Cross-national patterns. International Studies of Management \& Organization, 45(2), pp. 121-136.

30. H.-M. Aula, J. Tienari and A. Wæraas (2015) The university branding game: Players, interests, and politics. International Studies of Management \& Organization, 45(2), pp. 164-179.

31. A. Kosmütski (2012) Between mission and market position: Empirical findings on mission statements of German higher education institutions. Tertiary Education and Management, 18(1), pp. 57-77.

32. T.C. Melewar and S. Akel (2006) The role of corporate identity in the higher education sector: A case study. Corporate Communications: An International Journal, 10(1), pp. 41-57.

33. G.S. Drori and L. Beserman-Navon (Forthcoming) Mediatization of academia in Israel: Advertising by universities and colleges, 2000-2015. Megamot, (Hebrew).

34. H. Osman (2008) Re-branding academic institutions with corporate advertising: A genre perspective. Discourse and Communication, 2(1), pp. 57-77.

35. A. Wæraas and M.N. Solbakk (2009) Defining the essence of a university: Lessons from higher education branding. Higher Education, 57(4), pp. 449-462.

36. B.J. Gray, K.S. Fam and V.A. Llanes (2003) Branding universities in Asian markets. Journal of Product \& Brand Management, 12(2), pp. 108-120.

37. I. Holmberg and L. Strannegård (2015) Students' self-branding in a Swedish business school. International Studies of Management \& Organization, 45(2), pp. $180-192$.

38. C. Chapleo (2011) Exploring rationales for branding a university: Should we be seeking to measure branding in UK universities? Journal of Brand Management, 18(6), pp. 411-422.

39. G.S. Drori, G. Delmestri and A. Oberg (2013) Branding the university: Relational strategy of identity construction in a competitive field, In: Lars Engwall and Peter Scott (Eds), Trust in Higher Education Institutions (London: Portland Press), pp. 134-147.

40. A. Oberg, G.S. Drori and G. Delmestri (Forthcoming) Where history, visuality and identity meet: Institutional paths to visual diversity among organizations. In: M.A. Höllerer, T. Daudigeos and D. Jancsary (Eds), Research in the Sociology of Organizations: Multimodality, Meaning and Institutions (Bingley, UK: Emerald).

41. G.S. Drori, G. Delmestri and A. Oberg (2016) The iconography of universities as institutional narratives. Higher Education, 71(2), pp. 174-177. 
42. M. Kornberger (2009) The Brand Society: How Brands Transform Management and Lifestyle (Cambridge: Cambridge University Press).

43. G.S. Drori and J.W. Meyer (2006) Scientization: Making a world safe for organizing. In: M.-L. Djelic and K. Sahlin-Andersson (Eds), Transnational Governance: Institutional Dynamics of Regulation (Cambridge: Cambridge University Press), pp. 32-52.

44. T.F. Gieryn (1999) Cultural Boundaries of Science: Credibility on the Line (Chicago: The University of Chicago Press).

45. B. Ernst and A. Kieser (2002) In search of explanations for the consulting explosion. In: K. Sahlin-Andersson and L. Engwall (Eds), The Expansion of Management Knowledge: Carriers, Flows, and Sources (Stanford, CA: Stanford University Press), pp. 47-73.

46. G.S. Drori (2016) Professional consultancy and global higher education: The case of branding of academia. In: A. Verger, C. Lubienski and G. SteinerKhamsi (Eds), The Global Education Industry (World Yearbook of Education 2016) (London: Routledge), pp. 175-189.

47. K. Serrano-Velarde and G. Krücken (2012) Private sector consultants and public universities: The challenges of cross-sectoral knowledge transfers. European Journal of Education, 47(2), pp. 277-289.

48. D. Strang and J.W. Meyer (1993) Institutional conditions for diffusion. Theory and Society, 22(4), pp. 487-511.

49. D. Rémillard (13 March 2016) Une pub de l'Université Laval comparée à un monument nazi. Le Soleil, http://www.lapresse.ca/le-soleil/actualites/education/ 201603/13/01-4960184-une-pub-de-luniversite-laval-comparee-a-un-monumentnazi.php (accessed 5 August 2017).

50. K.H. Mok and Y. Chan (2008) International benchmarking with the best universities: Policy and practice in mainland China and Taiwan. Higher Education Policy, 21(4), pp. 469-486.

51. This includes the identification of better processes, the description of strengths and weaknesses with reference to the ideal model and the embrace of management-skill development. J. Nazarko, K.A. Kuźmicz, E. Szubzda-Prutis and J. Urban (2009) The general concept of benchmarking and its application in higher education in Europe. Higher Education in Europe, 34(3-4), pp. 498.

52. D.A. Gioia, M. Schultz and K.G. Corley (2000) Organizational identity, image, and adaptive instability. Academy of Management Review, 25(1), pp. 63-81.

53. For example, J. Owen-Smith (2003) From separate systems to a hybrid order: Accumulative advantage across public and private science at research one universities. Research Policy, 32(6), pp. 1081-1104.

54. J. Tuunainen and T. Knuuttila (2009) Intermingling academic and business activities: A new direction for science and universities? Science, Technology, \& Human Values, 34(6), pp. 684-704.

55. M. Van den Brink and Y. Benschop (2011) Gender practices in the construction of academic excellence: Sheep with five legs. Organization, 19(4), p. 508.

56. M. Lamont (2009) How Professors Think: Inside the Curious World of Academic Judgment (City: Harvard University Press).

57. E. Wilf (2015) Routinized business innovation: An undertheorized engine of cultural evolution. American Anthropologist, 117(4), p. 689.

58. A. Hearn (2010) 'Through the looking glass': The promotional university 2.0. In: M. Aronczyk and D. Powers (Eds), Blowing Up the Brand: Critical Perspectives on Promotional Culture (New York: Peter Lang), pp. 197-219. 


\section{About the Author}

Gili S. Drori is Associate Professor of Sociology and Anthropology at The Hebrew University of Jerusalem, in Israel. Her publications speak to her research interests in globalization and glocalization; governance and rationalization; world society theory; science, innovation and higher education; and, culture, knowledge and policy regimes. She has received academic degrees from Tel Aviv University (BA, 1986; MA, 1989) and Stanford University (PhD, 1997, sociology). 